\title{
COVID toes: A unique cutaneous indicator of COVID-19
}

\author{
Travis S. Dowdle BS, Todd K. Brown BS, Joshua A. Peterson BS, Kiana Banafshay BSA, \\ Jeannie M. Nguyen MD, Ashley L. E. Sturgeon MD
}

\begin{abstract}
Background: This brief review considers major aspects of COVID toes as currently understood. Topics discussed include etiology, pathophysiology, differential diagnosis, treatment, and management. Media characterization, potentially leading to intense public interest in COVID toes during the summer of 2020, is also discussed.

Methods: The literature review was conducted by selecting articles from PUBMED, SCOPUS, EMBASE, and Google Scholar based on the relevance to our topic. To determine the relative search interest of the general population, a Google Trends analysis was queried on $11 / 17 / 20$ for the retrospective duration of 11/17/2019-11/17/2020.

Results: The majority of patients who have presented with COVID toes are children and young adults. COVID toes generally present as acro-ischemic lesions, which are microthrombotic events in the extremities, leading to symptoms such as pseudo-chilblains or pernio-like lesions. Chilblains are histologically classified as an inflammatory disorder with a prominent perivascular lymphocytic infiltrate seen on microscopy. The regions are described as appearing erythematous to purple purpuric macules, papules, and/or vesicles. In many cases, COVID toes symptoms are self-limiting.

Conclusion: The development of COVID toes represents an additional manifestation of COVID-19 that should lead to additional testing. Knowledge of these symptoms can give healthcare workers and the general public another tool for recognizing COVID-19.
\end{abstract}

Keywords: COVID toes, COVID-19, coronavirus, chilblains, pernio

\section{INTRODUCTION}

As the world continues to study SARS-CoV-2 and attempts to control it through vaccine distribution and other public health measures, it is still important for the healthcare community and general public to recognize and respond to the atypical symptoms associated with COVID-19. Loss of smell and taste are some of the earliest recognized, distinct manifestations of a COVID-19 infection; however, there are also dermatologic manifestations associated with the disease, most

Corresponding author: Ashley Sturgeon

Contact Information: Ashley.Sturgeon@ttuhsc.edu

DOI: 10.12746/swrccc.v9i39.845 prominently, COVID toes. Patients, especially children and adolescents, have presented with red-purple, tender, itchy bumps that develop mostly on the toes, but also on the heels and fingers. These findings resemble perniosis or chilblains, a rash that is typically associated with exposure to cold conditions.

Widespread contemporary media coverage of COVID toes existed in the summer of 2020 , in attempts to explain the potential association of COVID toes with COVID-19 (Table 1). The main goal of the media was to educate the public on what this unique symptom might mean for them. It also should be noted that during this time, widespread testing in the U.S. was limited and discovery of unique symptomatology for potential exposure was particularly relevant. A variety of media narratives existed, leading to intense public interest. 
Table 1. Major News Outlets Covering COVID Toes

\begin{tabular}{|c|c|c|}
\hline News Outlet Website & $\begin{array}{c}\text { Date } \\
\text { Published } \\
\end{array}$ & Title of Article \\
\hline Abcnews.com & $04 / 20 / 20$ & COVID Toes': Could skin conditions offer coronavirus clues? \\
\hline Foxnews.com & $04 / 20 / 20$ & Doctors research 'COVID toes' theory in hopes to find new coronavirus clue \\
\hline Yahoo.com & $04 / 20 / 20$ & $\begin{array}{l}\text { What are 'COVID toes' and why are dermatologists seeing an 'epidemic' of } \\
\text { them in kids? }\end{array}$ \\
\hline usatoday.com & $04 / 21 / 20$ & $\begin{array}{l}\text { What are 'COVID toes'? Doctors discover symptom of coronavirus mostly } \\
\text { seen in kids }\end{array}$ \\
\hline Northwestern.edu & $04 / 21 / 20$ & COVID toes probably more rampant than we realize' \\
\hline Businessinsider.com & $04 / 23 / 20$ & $\begin{array}{l}\text { 'COVID toes' might be the latest unusual sign that people are infected with } \\
\text { the novel coronavirus }\end{array}$ \\
\hline Dailyherald.com & $04 / 24 / 20$ & COVID toes' reported in some patients with the coronavirus \\
\hline Forbes.com & $04 / 27 / 29$ & Spots On Toes And Rashes Join Weird New Symptoms Of Coronavirus \\
\hline Time.com & $04 / 28 / 20$ & $\begin{array}{l}\text { From 'COVID Toes' to Hives, These Are the Skin Conditions Dermatologists } \\
\text { Think Could Be Signs of Coronavirus }\end{array}$ \\
\hline Washingtonpost.com & $04 / 29 / 20$ & $\begin{array}{l}\text { 'Frostbite' toes and other peculiar rashes may be signs of hidden coronavirus } \\
\text { infection, especially in the young }\end{array}$ \\
\hline Everydayhealth.com & $04 / 30 / 20$ & $\begin{array}{l}\text { What Are 'COVID Toes'? Must-Know Facts About the Strange Coronavirus } \\
\text { Symptom }\end{array}$ \\
\hline NYtimes.com & $05 / 01 / 20$ & 'COVID Toes,' Other Rashes Are Latest Possible Rare Virus Signs \\
\hline Cbsnews.com & $05 / 02 / 20$ & "COVID toes" and other skin symptoms may be a sign of coronavirus \\
\hline Bbc.com & $05 / 02 / 20$ & Coronavirus: 'Covid toe' and other rashes puzzle doctors \\
\hline Usnews.com & $05 / 04 / 20$ & More Symptoms of Coronavirus: COVID Toes, Skin Rashes \\
\hline Npr.com & $05 / 06 / 20$ & $\begin{array}{l}\text { From Loss Of Smell To ‘COVID Toes’: What Experts Are Learning About } \\
\text { Symptoms }\end{array}$ \\
\hline Cnn.com & $05 / 08 / 20$ & 'Covid toes' may be a sign you had coronavirus \\
\hline Medscape.com & $05 / 08 / 20$ & 'COVID Toes' and 'Kawasaki’ Rash: 5 Cutaneous Signs in COVID-19 \\
\hline Massgeneral.org & $05 / 08 / 20$ & $\begin{array}{l}\text { TRACKING “COVID TOES” AND DERMATOLOGIC SYMPTOMS OF } \\
\text { COVID-19 }\end{array}$ \\
\hline Healio.com & $05 / 14 / 20$ & 'COVID-toes,' tracking dermatological symptoms of COVID-19 \\
\hline Apnews.com & $05 / 17 / 20$ & 'COVID toes,' other rashes latest possible rare virus signs \\
\hline Snopes.com & $05 / 17 / 20$ & 'COVID Toes,' Other Rashes Are Latest Possible Rare Virus Signs \\
\hline Scientificamerican.com & $05 / 18 / 20$ & $\begin{array}{l}\text { From Headaches to 'COVID Toes,' Coronavirus Symptoms Are a Bizarre } \\
\text { Mix }\end{array}$ \\
\hline Nationalgeographic.com & $05 / 21 / 20$ & $\begin{array}{l}\text { Inflamed brains, toe rashes, strokes: Why COVID-19's weirdest symptoms } \\
\text { are only emerging now }\end{array}$ \\
\hline Med.wisc.edu & $06 / 11 / 20$ & $\begin{array}{l}\text { "Covid toes" clinical trial underway at UW school of medicine and public } \\
\text { health }\end{array}$ \\
\hline
\end{tabular}

(continued) 
Table 1. Major News Outlets Covering COVID Toes (Continued)

\begin{tabular}{|l|c|l|}
\hline News Outlet Website & $\begin{array}{c}\text { Date } \\
\text { Published }\end{array}$ & Title of Article \\
\hline Webmd.com & $06 / 25 / 20$ & 'COVID Toe' Probably Not Caused by COVID-19 \\
\hline Jamanetwork.com & $06 / 25 / 20$ & Focus on “COVID Toes”' \\
\hline Health.clevelandclinic.org & $06 / 30 / 20$ & Are COVID Toes and Rashes Common Symptoms of the Coronavirus? \\
\hline Sciencedaily.com & $07 / 02 / 20$ & Study supports link between COVID-19 and COVID toes \\
\hline Weillcornell.org & $07 / 09 / 20$ & COVID Toe and Other COVID-19 Skin Conditions \\
\hline AAD.org & $07 / 13 / 20$ & $\begin{array}{l}\text { COVID TOES, RASHES: HOW THE CORONAVIRUS CAN AFFECT } \\
\text { YOUR SKIN }\end{array}$ \\
\hline Idse.net & $08 / 19 / 20$ & COVID Toes: Managing This Unusual COVID-19 Manifestation \\
\hline
\end{tabular}

For instance, some media outlets described COVID toes as having a frostbite appearance on hands and toes. ${ }^{1}$ Others reassured the public that these symptoms were not a sign of major concern, but rather indicated that their immune system was at work. ${ }^{2}$ Still, similar to a few articles in the primary literature, some continued to express uncertainty regarding a definite association between COVID toes and COVID-19 as more research needed to be done. ${ }^{3}$ While a wide number of media outlets covered this topic, the overall consensus remained that these symptoms were adequate grounds to get tested. The list of news outlets found in Table 1 does not include the numerous local news outlets that also reported similar stories during the same time period, likewise, increasing public interest.

Research and knowledge about COVID-19 is increasing, and this brief review succinctly summarizes the current understanding of COVID toes with the following objectives:

- Describe the etiology, pathophysiology, differential diagnosis, treatment and management of COVID toes.

- Explore media characterization of COVID toes with associated patient perceptions due to this popular search topic in the summer of 2020 and reconcile these findings with the dermatologic primary literature.

- Juxtapose competing theories regarding whether chilblain lesions are related to COVID-19.
- Provide recommendations and salient information for healthcare workers, patients, and their families.

\section{Methods}

To objectively determine the relevance of public interest in "COVID toes" in comparison with other unique symptoms of COVID-19, Google Trends was queried on 11/17/20 to establish relative search volumes of unique symptomology of COVID-19. Loss of smell, loss of taste, shortness of breath, and COVID toes were the four unique search terms compared via relative search volume with values of 0 being no queries being elicited during the specific time frame analyzed, and 100 belonging to the most popular search term during the same time frame.

Google Trends is an open-source database that allows data comparison by geography, timeframe, and search term. Comparisons can be refined by selecting specific sub-category classifications and also filtered by type of search, including web, images, news and YouTube if necessary. We selected "United States" as our geographical search area of interest, selected 12 months of continuous, retrospective data from 11/17/2019-11/17/2020, chose "All categories", and filtered by web searches specifically. ${ }^{4}$

Search history indicates that this topic has been of significant search interest to the public in the United States, rivaling other unique symptoms of COVID-19, such as shortness of breath and loss of taste and 


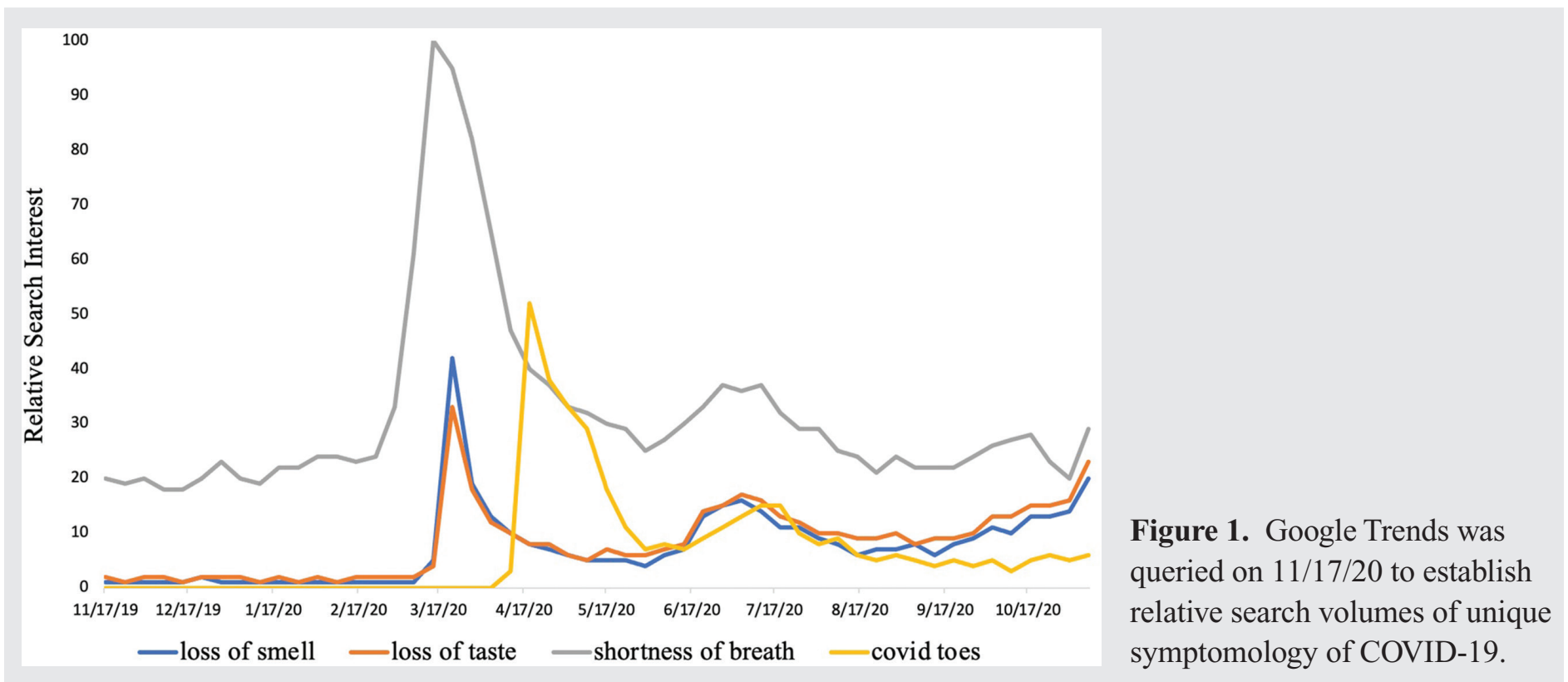

smell. To establish the extent of news media coverage during the height of search interest, Google Tools was queried with the search "Covid Toes" from 04/01/20 08/31/20 (Figure 1). Table 1 was subsequently built from the first 10 pages of results.

Because of the limited number of publications related to COVID toes and cutaneous symptomology of COVID-19 generally, articles were selected from PUBMED, SCOPUS, EMBASE, and Google Scholar contingent on the relevance to our literature review.

\section{Discussion}

\section{Pathophysiology of COVID}

COVID-19 is best understood through its pathogenesis and transmission. SARS-CoV-2 is a positive-strand RNA virus that is the cause of COVID-19. ${ }^{5}$ The principal receptor for SARS-CoV-2 is the angiotensinconverting enzyme 2 (ACE2) receptor, which is widely distributed among cell membranes of various organs, including the lungs. ${ }^{6}$ ACE2 usually has an essential role in negatively regulating the renin-angiotensin aldosterone system (RAAS), a system responsible for modulating blood volume and systemic vascular tone. ${ }^{7}$ However, upon binding ACE2, SARS-CoV-2 enters the host cell through endocytosis and subsequently leads to ACE2 downregulation. ${ }^{8}$ As a result, an increase in angiotensin II is observed, promoting lung injury via inflammatory pathway activation.

Transmission of COVID-19 is advanced by respiratory droplets in the air from close person-to-person contact by coughing, sneezing, and hand-to-mouth contact. ${ }^{9}$ Both symptomatic and asymptomatic individuals can spread infection.

\section{Pathophysiology of COVID toes}

The majority of patients who have presented with COVID toes are children and young adults. ${ }^{10}$ COVID toes generally present as acro-ischemic lesions, which are microthrombotic regions in the extremities, leading to symptoms such as pseudo chilblains or pernio like lesions (Figure 2). ${ }^{11}$ Chilblains are histologically classified as an inflammatory disorder with a prominent perivascular lymphocytic infiltrate seen on microscopy. ${ }^{12}$ The regions are described as appearing 'erythematous to purple purpuric macules, papules, and/or vesicles'. ${ }^{13}$ In many cases, COVID toes symptoms are self-limiting. ${ }^{10}$

These symptoms can occur after, during, or before other COVID-19 symptoms. Of the confirmed patients 


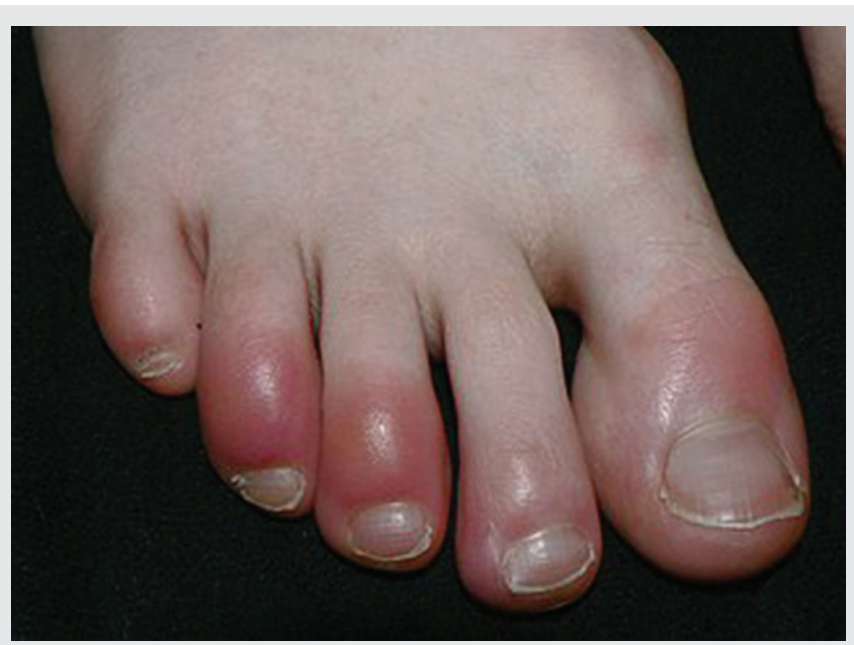

Figure 2. Typical chilblain toes. (Source-Wikipedia. https://en.wikipedia.org/wiki/File:Wintertenen.jpg)

having both COVID-19 and dermatological symptoms, $64 \%$ of the dermatological symptoms presented after the COVID-19 illness, 15\% presented simultaneously with other symptoms, and $12 \%$ occurred before other symptoms. ${ }^{14}$

\section{OtheR SYMPTOMS With COVID-19}

While cough and shortness of breath are major symptoms of COVID-19, other less conspicuous symptoms, such as loss of smell (anosmia) and taste (ageusia) have been noted. Anosmia is caused by SARS-CoV-2 damage to sustentacular cells of olfactory epithelium that express the ACE2 receptor. ${ }^{15}$ The ACE2 receptor is also found in other extrapulmonary tissues, such as the gastrointestinal tract, making these tissues vulnerable to infection. ${ }^{16}$

Recently, a rise in cutaneous manifestations in COVID-19 patients has been identified, further increasing interest in the link between SARS-CoV-2 and the skin. Skin manifestations of COVID-19 patients include erythematous rashes appearing around the onset of symptoms, vesicular eruptions around the trunks and limbs, and urticaria. ${ }^{17}$ The appearance of chilblains, or COVID toes, has also been noted. While a definite causative relationship has not been established, one study found that damage to the endothelium by the
COVID-19 virus could explain the pathogenesis of COVID toes. ${ }^{18}$

\section{Differential Diagnosis}

During the duration of the COVID-19 pandemic, the presentation of chilblain lesions may justifiably lead healthcare workers to attribute these symptoms to the virus. Despite the association of COVID toes with COVID-19, other etiologies of chilblain lesions should be considered.

Presentations of chilblain lesions (synonymous with perniosis) may be due to primary or secondary perniosis. Symptoms of perniosis present similarly to what has been described as COVID toes, namely, vasospasm and acro-ischemia of unknown etiology leading to "painful and pruritic erythrocyanotic discoloration and swelling." 19 Perniosis usually requires a trigger of exposure to cool, but non-freezing temperatures. While primary perniosis occurrence is idiopathic, secondary perniosis occurs due to an underlying systemic cause. ${ }^{20}$ Various autoimmune immune disorders (systemic lupus erythematosus, sarcoidosis, vasculitides, antiphospholipid disease, and others) have been implicated in secondary perniosis. ${ }^{19}$ As such, personal and family history of autoimmune disease and recent exposure to cold temperatures ought to be considered with possible COVID-19 infection in patients presenting with chilblain lesions. Other non-COVID-19-related presentations of chilblain lesions include leukemia cutis (cutaneous presentations of leukemia) and familial lupus chilblains. ${ }^{20}$

\section{MANAGement}

Chilblain lesions identified during COVID-19 infection tend to be self-limiting. A retrospective review and follow-up of 22 children and adolescents who presented to the emergency department with COVID toes symptoms in Spain in April 2020 revealed that lesions resolved spontaneously. Symptoms generally started to fade 7-10 days after presentation at the hospital and were markedly improved or completely resolved after $3-5$ weeks in all patients. ${ }^{21}$ Another 
retrospective review of 26 children with COVID toes in Italy in March-April 2020 also demonstrated that all patients recovered without any treatment. ${ }^{22}$ In these studies and other published case reports, a variety of treatments have been used. Patients have received symptomatic treatment (oral analgesia and antihistamines), topical heparin, topical nitroglycerin, and topical and systemic corticosteroids. ${ }^{21-24}$ To date, no randomized control trials have been performed to assess the efficacy of treatment for COVID toes.

\section{Alternative theories}

The association between COVID toes and COVID-19 has been highly debated. The sudden and rapid increase of symptoms associated with COVID toes during the rise of COVID-19 cases indicates that there is a relationship between the two; however, the lack of confirmatory testing does not allow confirmation of an association. ${ }^{10}$ Testing and research conducted on the association between COVID-19 and COVID toes provide competing theories on the cause COVID toes. Positive anti-SARS-CoVISARS-CoV-2 immunostaining on skin lesions from individuals presenting with chilblain-like lesions appears to show the virus in the skin lesions, but it lacks specificity. ${ }^{25}$

On the contrary, Baeck and Herman cite several studies that demonstrate that RT-PCR and antiSARS-CoV-2 serology were negative in the majority of patients that had chilblain-like lesions, indicating that COVID toes may present without a patient being seropositive for COVID-19. These authors also explored the possibility that COVID toes could be a cutaneous expression of type I interferon (IFN-I) response; however, a lack of other symptoms only raises further questions about this hypothesis. An additional alternative provided by Baeck and Herman is that COVID toes may be related to lifestyle changes during COVID-19 lockdowns, including more sedentary lifestyles and exposure to cold floor surfaces. ${ }^{25}$

\section{Conclusion}

Knowledge of COVID toes may help healthcare workers and the general public recognize and diagnose potential cases of COVID-19, especially in cases with few other symptoms. ${ }^{26}$ For example, of the confirmed COVID-19 cases compiled in a dermatological study, $19 \%$ of the patients presented with pernio-like lesions without other COVID-19 symptoms present. ${ }^{14}$

We propose that more awareness about COVID toes in the healthcare community and the public will help all recognize this potential symptom of COVID19. Adolescents and parents of children and adolescents particularly, should be alert to the appearance of chilblain lesions in the skin of extremities, recognizing that these symptoms serve as adequate grounds to get tested for COVID-19 in conjunction with a possible COVID-19 exposure. While we recognize that such association between COVID toes and COVID19 is not definite, continued research and awareness could aid in diagnosis, treatment, and containment of COVID-19. Because of the intense public interest that existed in the summer of 2020 , healthcare workers may continue to receive questions regarding this cutaneous manifestation of COVID-19.

Article citation: Dowdle TS, Brown TK, Peterson JA, Banafshay K, Nguyen JM, Sturgeon ALE. COVID toes: A unique cutaneous indicator of COVID-19. The Southwest Respiratory and Critical Care Chronicles 2021;9(39):15-21 From: Texas Tech University Health Sciences CenterSchool of Medicine (TSD, JAP, KB) Lubbock, Texas; Imperial College of Science, Technology, and MedicineBusiness School (TKB), London, UK; Department of Dermatology (JMN, AES) Texas Tech University Health Sciences Center, Lubbock, Texas

Submitted: $2 / 28 / 2021$

Accepted: 4/1/2021

Reviewer: Drew Payne DO Conflicts of interest: none This work is licensed under a Creative Commons Attribution-ShareAlike 4.0 International License.

\section{REFERENCES}

1. Reinberg, Steven. More Symptoms of Coronavirus: COVID Toes, Skin Rashes | Health News | US News. Accessed January 3, 2021. https://www.usnews.com/news/health-news/ 
articles/2020-05-04/more-symptoms-of-coronavirus-covidtoes-skin-rashes

2. ChaAE. 'Frostbite' toes and other peculiar rashes may be signs of hidden coronavirus infection, especially in the young. Washington Post. https:/www.washingtonpost.com/health/2020/ 04/29/coronavirus-rashes-toes/. Accessed January 3, 2021.

3. Ducharme J. Skin Rashes Like "COVID Toes" May Be Signs of Coronavirus | Time. Accessed February 24, 2021. https:// time.com/5827912/coronavirus-skin-rashes/

4. Coronavirus Search Trends. Google Trends. Accessed January 3, 2021. https://trends.google.com/trends/story/US_cu_ 4Rjdh3ABAABMHM_en

5. Zamorano Cuervo N, Grandvaux N. ACE2: Evidence of role as entry receptor for SARS-CoV-2 and implications in comorbidities. Elife 2020;9. doi:10.7554/eLife.61390

6. Anka AU, Tahir MI, Abubakar SD, et al. Coronavirus disease 2019 (COVID-19): An overview of the immunopathology, serological diagnosis and management. Scandinavian Journal of Immunology. n/a(n/a): e12998. doi: https://doi.org/ 10.1111/sji.12998

7. Cure E, Cumhur Cure M. Comment on "Organ-protective effect of angiotensin-converting enzyme 2 and its effect on the prognosis of COVID-19." J Med Virol 2020;92(9): 1423-1424.

8. Banu N, Panikar SS, Leal LR, Leal AR. Protective role of ACE2 and its downregulation in SARS-CoV-2 infection leading to Macrophage Activation Syndrome: Therapeutic implications. Life Sci 2020;256:117905. doi: 10.1016/j.lfs.2020. 117905

9. Machhi J, Herskovitz J, Senan AM, et al. The natural history, pathobiology, and clinical manifestations of SARS-CoV-2 Infections. J Neuroimmune Pharmacol Published online July 21, 2020:1-28.

10. Landa N, Mendieta Eckert M, Fonda Pascual P, Aguirre T. Chilblain-like lesions on feet and hands during the COVID19 Pandemic. International J Dermatology 2020;59(6): 739-743.

11. Seirafianpour F, Sodagar S, Mohammad AP, et al. Cutaneous manifestations and considerations in COVID-19 pandemic: A systematic review. Dermatol Ther Published online July 8, 2020. doi:10.1111/dth.13986

12. Massey PR, Jones KM. Going viral: A brief history of Chilblain-like skin lesions ("COVID toes") amidst the COVID-19 pandemic. Seminars in Oncology. 2020;47(5): 330-334.

13. Hernandez C, Bruckner AL. Focus on "COVID Toes." JAMA Dermatol 2020;156(9):1003. doi:10.1001/jamadermatol.2020. 2062
14. Freeman EE, McMahon DE, Lipoff JB, et al. The spectrum of COVID-19-associated dermatologic manifestations: An international registry of 716 patients from 31 countries. $\mathrm{J} \mathrm{Am}$ Acad Dermatol 2020;83(4):1118-1129.

15. Bilinska K, Jakubowska P, Von Bartheld CS, et al. Expression of the SARS-CoV-2 entry proteins, ACE2 and TMPRSS2, in cells of the olfactory epithelium: identification of cell types and trends with age. ACS Chem Neurosci 2020;11(11):1555-1562.

16. Burgueño JF, Reich A, Hazime $H$, et al. Expression of SARS-CoV-2 Entry Molecules ACE2 and TMPRSS2 in the Gut of Patients With IBD. Inflamm Bowel Dis. Published online April 25, 2020. doi:10.1093/ibd/izaa085

17. Garduño-Soto M, Choreño-Parra JA, Cazarin-Barrientos J. Dermatological aspects of SARS-CoV-2 infection: mechanisms and manifestations. Arch Dermatol Res Published online November 6, 2020:1-12.

18. Colmenero I, Santonja $C$, Alonso-Riaño $M$, et al. SARSCoV-2 endothelial infection causes COVID-19 chilblains: histopathological, immunohistochemical and ultrastructural study of seven paediatric cases. British Journal of Dermatology 2020;183(4):729-737.

19. Nyssen A, Benhadou F, Magnée M, André J, et al. Chilblains. Vasa. 2020;49(2):133-140.

20. Zaladonis A, Huang S, Hsu S. COVID toes or pernio? Clinics in Dermatology 2020;38(6):764-767.

21. Andina D, Noguera-Morel L, Bascuas-Arribas M, et al. Chilblains in children in the setting of COVID-19 pandemic. Pediatric Dermatology 2020;37(3):406-411.

22. Gallizzi R, Sutera D, Spagnolo A, et al. Management of pernio like cutaneous manifestations in children during the outbreak of covid 19. Dermatol Ther Published online September 19, 2020. doi:10.1111/dth.14312

23. Weingarten $M$, Abittan B, Rivera-Oyola R, Abittan AI, Weingarten M, Lebwohl M. Treatment of COVID-19 induced chilblains with topical nitroglycerin. Int $J$ Dermatol 2020;59(12):1522-1524.

24. Ruggiero G, Arcangeli F, Lotti T. Therapy for probable COVID-19 associated erythema pernio-like lesions in pediatric age. Case report. Dermatol Ther 2020;33(4):e13616. doi:10.1111/dth.13616

25. Baeck M, Herman A. COVID toes: where do we stand with the current evidence? International Journal of Infectious Diseases 2021;102:53-55.

26. Casas CG, Català $\mathrm{A}$, Hernández GC, et al. Classification of the cutaneous manifestations of COVID-19: a rapid prospective nationwide consensus study in Spain with 375 cases. British J Dermatology 2020;183(1):71-77. 